\title{
The Atrioventricular Junctional Network-An Unfinished Map
}

Jon Lomasney ${ }^{1}$ and Rachel Kaplan ${ }^{2}$

${ }^{1}$ Northwestern University Feinberg School of Medicine

${ }^{2}$ Northwestern University, Feinberg School of Medicine

May 15, 2021

\section{Hosted file}

J cardio Electro Editorial JCE-20-1694.R1.pdf available at https://authorea.com/users/413887/ articles/522069-the-atrioventricular-junctional-network-an-unfinished-map 